\title{
Pagane Mythen - christliche Herrscher. Mythos und Mythologie in den politischen Dichtungen Claudians
}

Kaum eine Frage hat die Forschungen zu Claudian so kontinuierlich und so intensiv beschäftigt wie diejenige nach der Konfession dieses Dichters, ${ }^{1}$ der, wahrscheinlich aus dem ägyptischen Alexandria stammend, ${ }^{2}$ seit 395 n.Chr. als Hofdichter in den Diensten des weströmischen Kaiserhofes stand. Dabei scheint die Sachlage auf den ersten Blick unzweifelhaft. Nach den Zeugnissen zweier christlicher Zeitgenossen war Claudian kein Christ: „Ohne Verbindung zum christlichen Glauben“, a Christi nomine alienus, hat Augustinus sein Werk im fünften Buch seines Gottesstaates genannt, ${ }^{3}$ einen „unbekehrbaren Heiden“, paganus pervicacissimus, gar der Historiker Orosius. ${ }^{4}$ Die überlieferten Dichtungen Claudians scheinen ihnen Recht zu geben: Nicht nur wählt sich Claudian für sein Epos De raptu Proserpinae einen dezidiert nichtchristlichen Stoff, nicht nur lassen seine Carmina minora mit Ausnahme des häufig als unecht erachteten Gedichts De salvatore ${ }^{5}$ keinerlei Bezüge zum Christentum erkennen. Auch die politischen Dichtungen, die Claudian zwischen 395 und 404 für hohe Würdenträger und Angehörige des weströmischen Kaiserhofs verfasste, blenden das Christentum vollständig aus. „Es ist“, so schreibt Siegmar Döpp, ,als ob es für den politischen Dichter Claudian das Christentum nicht gäbe; vielmehr könnte man aus seinen Werken den Eindruck gewinnen, das Heidentum lebe mit ungebrochener Kraft fort“ “ ${ }^{6}$ Der älteren Claudian-Forschung galt der Dichter daher gern als ,ausgemachter Heide“ und als ,letzter großer Dichter des paganen Roms‘. Alan Cameron überschreibt ein

1 Zuletzt: H. Harich-Schwarzbauer, Dokumentation, Historisierung, gelehrte Andeutung und spielerische Erhaltung: Zur literarischen Repräsentation philosophischer Diskurse bei Claudius Claudianus, in: Th. Fuhrer (Hrsg.), Die christlich-philosophischen Diskurse der Spätantike: Texte, Personen, Institutionen, Stuttgart 2008, 347-362. Einen ausführlichen Forschungsüberblick gibt S. Döpp, Zeitgeschichte in Dichtungen Claudians, Wiesbaden 1980 (Hermes ES 43), 24-41; C. Moreschini, Paganus pervicacissimus? Religione e ,filosofia‘ in Claudiano, in: W.-W. Ehlers, F. Felgentreu, S. H. Wheeler (Hrsg.), Aetas Claudianea, München - Leipzig 2004, 57-77, 57-59.

2 Die ägyptische Herkunft Claudians wurde bezweifelt von P. G. Christiansen, Claudian - a Greek or a Latin, Scholia 6 (1997), 79-95; überzeugend für eine Herkunft des Dichters aus dem Osten wieder B. Mulligan, The Poet From Egypt? Reconsidering Claudian's Eastern Origin, Philologus 151 (2007), 285 310 (erneuter Widerspruch von P. G. Christiansen/D. Christiansen, Claudian. The Last Great Pagan Poet, AntCl 78 [2009], 133-144).

3 Aug. civ. 5,68.

4 Oros. hist. 7,35.

5 Vgl. P. Fargues, Claudien. Etudes sur sa poésie et son temps, Paris 1933, $159 \mathrm{f}$.

6 Döpp (s. Anm. 1), 25f. Ähnlich H. L. Levy, Themes of Encomium and Invective in Claudian, TAPA 89 (1958), 336-347, 345: „Claudian writes as if the old Roman state religion were in full bloom throughout the Empire.“ 
Kapitel seiner Monographie provokant mit dem Titel „The Pagan at a Christian Court“7 und zuletzt haben Peder G. Christiansen und David Christiansen 2009 Claudian als „The Last Great Pagan Poet“ tituliert. ${ }^{8}$ Die neuere Forschung hat indes nachgewiesen, dass diese Einschätzung weitaus problematischer ist, als es zunächst den Anschein hat. ${ }^{9}$ Fakt ist zwar, dass Claudian in seinen Dichtungen auf explizite Bezüge zum Christentum verzichtet. Ebenso evident ist jedoch, dass er fast zehn Jahre lang als offizieller Hofdichter in den Diensten des Honorius, eines Sohnes des christianissimus imperator Theodosius, und seines vandalischen Heermeisters und Vormunds Stilicho gewirkt hat und für seine poetischen Leistungen sogar mit einer Statue auf dem Trajansforum geehrt wurde, deren Sockelinschrift erhalten ist. Wie hat man sich also das offensichtliche Miteinander von paganen ${ }^{10}$ Dichtungen und christlichen Auftraggebern zu erklären? Sind Claudians Gedichte und die Tatsache, dass er mit ihnen über ein Jahrzehnt die öffentliche Meinung entscheidend prägte, ein Zeichen für die religiöse Toleranz Stilichos, wie frühe Claudian-Forscher wie Theodor Birt und Santo Mazzarino meinen ${ }^{11}$ Sollten Claudians Gedichte die heidnische Senatsaristokratie für Stilicho gewinnen? - dies die Vermutung von Harry Levy. ${ }^{12}$ Oder war Claudian ein „höfischer Scheinchrist“, so Wolfgang Schmid, ${ }^{13}$ der unter dem Deckmantel christlicher Konfession unbeirrt an seinen paganen Vorstellungen festhielt und diese in seinen Dichtungen kommunizierte?

Um es kurz zu machen: Ich glaube, dass es - gerade bei der Art von hochoffizieller, in vielfältige Traditionen eingebundener und verschiedensten Interessen verpflichteter Auftragsdichtung, die Claudian betreibt ${ }^{14}$ - extrem schwierig ist, aus seinen Dichtungen Rückschlüsse über seine persönliche religiöse Gesinnung abzuleiten, zumal neuere Untersuchungen gezeigt haben, dass zum einen das Verhältnis von Christen-

7 A. Cameron, Claudian. Poetry and Propaganda at the Court of Honorius, Oxford 1970, 189.

8 Christiansen/Christiansen (s. Anm. 2), 133-144.

9 Für die folgende Diskussion vgl. auch Döpp (s. Anm. 1), 24-41; C. Schindler, Claudians pagane Götter. Tradition und Innovation in der spätantiken Panegyrik, Gym 115 (2008), 331-345, 333- 335.

10 Der Begriff „pagan“, von christlichen Autoren zur Abgrenzung der eigenen Lehren geprägt, wird hier rein deskriptiv und wertneutral verwendt. Vgl. auch P. Gemeinhardt, Das lateinische Christentum und die pagane Bildung, Tübingen 2007, $21 \mathrm{f}$.

11 Th. Birt, De moribus christianis quantum Stilichonis aetate in aula imperatoria occidentali valuerint disputatio, Marburg 1885, xxiii; S. Mazzarino, La politica religiosa di Stilicone, Rendiconti/Istituto Lombardo, Accademia di Scienze e Lettere, Classe di Lettere, Scienze morali e storiche 71 (1938), 235262, hier: 245 f.; ähnlich Harich-Schwarzbauer (s. Anm. 1), 350.

12 Levy (s. Anm. 6).

13 W. Schmid, s.v. Claudianus I, RAC 3 (1957), 152-167, 160; Cameron (s. Anm. 7), 216.

14 Zur generischen Einordnung der Gedichte vgl. P. L. Schmidt, Politik und Dichtung in der Panegyrik Claudians, Konstanz 1976 (Konstanzer Universitätsreden 55); H. Hofmann, Überlegungen zu einer Theorie der nichtchristlichen Epik der lateinischen Spätantike, Philologus 132 (1988), 101-159; C. Schindler, Per carmina laudes. Untersuchungen zur spätantiken Verspanegyrik von Claudian bis Coripp, Berlin u.a. 2009 (Beiträge zur Altertumskunde 253); zuletzt G. Müller, Lectiones Claudianeae. Studien zu Poetik und Funktion der politisch-zeitgeschichtlichen Dichtungen Claudians, Heidelberg 2011 (Bibliothek der Klassischen Altertumswissenschaften, NF, 2. Reihe). 
tum und Kaisertum prinzipiell sehr viel komplexer ist, als es auf den ersten Blick erscheint, ${ }^{15}$ dass zum anderen der Umgang von Christen und Nichtchristen (die man ohnehin nicht dichotomisch trennen kann $)^{16}$ in vielen Bereichen kein kämpferisches Gegeneinander sein musste und dass pagane Traditionen in der Kunst, der Literatur und in der Philosophie mindestens bis ins fünfte Jahrhundert hinein weit verbreitet waren, ${ }^{17}$ so dass es nicht erstaunlich ist, dass ein prominenter Vertreter des Christentums wie Ambrosius seine Predigten mit antiken Mythologemen schmückte. ${ }^{18}$

Wie eine ganze Reihe anderer Claudian-Forscher glaube ich weiterhin, dass der Versuch, ein ,Glaubensbekenntnis‘ des Dichters zu ergründen, zum Verständnis seiner Dichtungen allenfalls begrenzt beizutragen vermag. ${ }^{19}$ Die Frage sollte meines Erachtens nicht lauten, ob Claudian ein ,Heide‘, ein ,Christ“ oder gar ein „höfischer Scheinchrist“ gewesen ist. Viel eher sollte man, wie es in der neueren Claudian-Forschung vermehrt geschieht, fragen, was den Hofdichter des theodosianischen Herrscherhauses bewogen haben kann, gerade in einem christlichen Kontext an achristlichen, aus dem gesamten Reservoir paganer Bildung gespeisten Dichtungen festzuhalten. Die Tendenz geht zumeist dahin, diese Frage mit dem Hinweis auf einen gewissen Traditionalismus Claudians zu beantworten: Pagane Elemente wie die Mythologie, so Cameron, „had long since become merely decorative“.${ }^{20}$ Die spätantiken Eliten seien in der paganen Bildungstradition erzogen worden, mit der zu brechen einem Dichter nicht ohne weiteres möglich gewesen sei. ${ }^{21}$

Doch lässt sich meines Erachtens mit dem Verweis auf pagane Bildungstraditionen die fast schon programmatisch achristliche Ausrichtung von Claudians Dichtungen nur zum Teil erklären. Am Beispiel der Verwendung eines Kristallisations-

15 Vgl. H. Leppin, Kaisertum und Christentum in der Spätantike. Überlegungen zu einer unwahrscheinlichen Synthese, in: A. Fahrmeir, A. Imhausen (Hrsg.), Die Vielfalt normativer Ordnungen. Konflikte und Dynamik in historischer und ethnologischer Perspektive, Frankfurt am Main 2013, 197 223.

16 Vgl. H. Leppin, Christianisierungen im Römischen Reich: Überlegungen zum Begriff und zur Phasenbildung, ZAC 16 (2012), 247-278, 249; 260.

17 Vgl. W. Liebeschuetz, Pagan Mythology in the Christian Empire, International Journal of the Classical Tradition 2 (1995), 193-208; Leppin (s. Anm. 16), $263 \mathrm{f}$.

18 Vgl. Cameron (s. Anm. 7), 199.

19 Aufschlussreich sind etwa die Ergebnisse von Harich-Schwarzbauer (s. Anm. 1), 360, zu Claudians hellenistischer Sozialisation in Alexandria im Umfeld der Neuplatoniker, die sie anhand der philosophischen Diskurse bei Claudian nachweist, wobei sie sich allerdings zu Claudians, Christentum nicht positioniert.

20 Cameron (s. Anm. 7), 199.

21 Vgl. zu dieser Forschungsdiskussion Schindler (s. Anm. 9), 335 (mit weiterführender Literatur). Für die Bedeutung der paganen Bildungstraditionen für die spätantike Elite außerdem Liebeschuetz (s. Anm. 17), $194 \mathrm{f}$. 
punktes vermeintlich paganer Gesinnung in Claudians politischen Dichtungen, des Mythos, ${ }^{22}$ möchte ich daher im Folgenden zeigen,

(1) dass gerade der Mythos bei Claudian im Kontext des Herrscherlobs eine wichtige Funktion übernimmt, die von christlichen Stoffen in dieser Form nicht geleistet werden kann, ${ }^{23}$

(2) dass Claudians Verwendung des Mythos nicht so sehr von Verehrung und Hochachtung gegenüber den paganen Kulturgütern zeugt als dass sie vielmehr eine kritische, beinahe schon destruktive Haltung des Dichters erkennen lässt,

(3) und schließlich, dass Claudians Rekurse auf den Mythos christliche Empfindungen nicht verletzen, sondern vielfach sogar mit ihnen konform gehen und bisweilen sogar dezidiert an die Mythenkritik christlicher Autoren anknüpfen.

\section{I. „Mythische Geographie“: Der Mythos als Bestandteil der römischen Literatur- und Kulturtradition}

Obgleich Mythologisches in Claudians politischen Dichtungen eine wichtige Rolle spielt, handelt es sich bei diesen Werken nicht um „mythologische“ Dichtungen im eigentlichen Sinn. Nicht Figuren des Mythos stehen im Mittelpunkt der Darstellung, sondern Persönlichkeiten der Zeitgeschichte, die als Adressaten der Gedichte teils nach den Vorgaben der rhetorischen Panegyrik verherrlicht, teils zu Protagonisten einer Handlung gemacht werden. ,Mythologisch' sind Claudians Panegyriken und Invektiven nur insofern, als sowohl die Protagonisten und ihre Gegenspieler als auch ihre Lebenswirklichkeit durch so gut wie alle politischen Dichtungen hindurch ${ }^{24}$ mit Gegebenheiten oder Figuren des Mythos in Verbindung gebracht werden. Dies geschieht zum Teil nur beiläufig und implizit. So wird die reale Welt in Claudians politischen Epen konsequent von mythischen Völker- und Ortsnamen überformt: Die Goten erscheinen stets ethnologisch unkorrekt als Getae, der Po heißt in Anspielung auf die PhaethonSage Eridanus. ${ }^{25}$ Häufig verbindet Claudian in seinen Gedichten mit geographischen

22 Der Mythendefinition von Chr. Schmitz, F. Zanella, S. Heydasch-Lehmann, s.v. Mythos, RAC 25 (2013), 471-516, 474, folgend, verstehe ich Mythen als „Erzählungen über Götter und Heroen“, vor allem in ihrer Manifestation als Narrative in literarisch-ästhetischen Diskursen.

23 Zur Unverzichtbarkeit des mythischen Stoffes s. Schmitzer in diesem Band.

24 Die Referenzdichte auf Mythologisches ist in den Gedichten etwa gleich hoch. Eine Ausnahme ist der Panegyricus für das Konsulat von Mallius Theodorus, der nur einen einzigen Verweis auf den Mythos enthält (283-295) - dies wohl deswegen, weil hier sehr stark auf die philosophischen Interessen des Mallius Theodorus abgehoben wird.

25 Z.B. Gild. 37; Stil. 1,111 (Getae); OlProb 259; III Cons. Hon. 123 (Eridanus); IV Cons. Hon. 508 (Res Pandioniae). Vgl. C. Schindler, Tradition-Transformation-Innovation. Claudians Panegyriken und das Epos, in: W.-W. Ehlers, F. Felgentreu, S. H. Wheeler (Hrsg.), Aetas Claudianea, München - Leipzig 2004, $16-37,21$. 
Angaben Hinweise auf ein mythisches Ereignis, um diesen Ort zu lokalisieren. So wird das ,Ende der Welt‘ in der Invektive gegen Rufin unter Verweis auf die odysseische Nekyia bestimmt: Fern im äußersten Gallien, am Rande des Ozeans, gebe es einen Ort, wo Odysseus nach der Überlieferung mit einem Blutopfer das Volk der Toten beschworen habe: ubi fertur Ulixes / sanguine libato populum movisse silentem (Ruf. 1,124f.). Zweifellos sind derartige Verweise auf den Mythos den generischen Konventionen der epischen Dichtung geschuldet, in denen Claudians Dichtungen stehen. ${ }^{26}$ Insbesondere die mythischen Ortsnamen sind dabei Gemeingut der Bildungstradition. Sie gehören dem Buchwissen der ,klassischen“ Antike an, einem Buchwissen, das „von jeder kultischen Bindung abgelöst“ ${ }^{“ 27}$ ist und dessen Spuren sich dementsprechend noch bei Venantius Fortunatus finden, wenn dieser die Hölle als Tartarus, den Himmel als Olympus und Jupiter als Tonans bezeichnet. ${ }^{28}$

Bei Claudian hat die ,mythische Geographie، jedoch eine wichtige Funktion, die sich besonders dort manifestiert, wo der Dichter in Verbindung mit geographischen Angaben in einer katalogartigen Aufzählung verschiedene Mythologeme präsentiert. Im zweiten Buch der Invektive gegen Eutrop zum Beispiel widmet er sich ausführlich der Landschaft Phrygien, die er als reiches und kulturträchtiges Land vorstellt (Eutr. 2,238-273). Phrygien ist nicht nur der Ursprung von Kultur und Sprache, sondern auch Schauplatz verschiedener mythologischer Ereignisse (Eutr. 2,255-261):

Hic cecidit Lyciis iactata paludibus olim 255 tibia, foedatam cum reddidit unda Minervam, hic et Apollinea victus testudine pastor suspensa memores inlustrat pelle Celaenas. quattuor hic magnis procedunt fontibus amnes auriferi; nec miror aquas radiare metallo, 260 quae totiens lavere Midan.

Hier fiel zu Boden die Flöte, die einst in die lykischen Sümpfe geschleudert wurde, als die Woge Minerva entstellt zurückwarf, hier macht der Hirte, von Apollons Lyra bezwungen, mit aufgehängter Haut Kelainai berühmt, das die Erinnerung an ihn bewahrte. Hier ergießen sich aus großen Quellen vier Gold führende Ströme, und ich wundere mich nicht, dass Wasser vom Goldglanz schimmern, die so oft den Midas badeten. ${ }^{29}$

Drei Mythen sind es, die der Dichter, gegliedert durch hic - hic - hic, mit Phrygien in Verbindung bringt: Es ist das Land, in dem Minerva aus Zorn über ihr entstelltes Spiegelbild ihre Flöte ins Wasser warf, Marsyas im Wettstreit dem Apoll unterlag und dessen goldschimmernde Flüsse auf den mythischen König Midas weisen. Abgesehen davon, dass die ausführliche Ekphrasis Phrygiens als Ganze die Schilderung der an-

26 Vgl. C. Ware, Claudian and the Roman Epic Tradition, Cambridge 2012, 42- 44.

27 Vgl. Schmitz (s. Anm. 22), 474.

28 Ven. Fort. laud. Mar. 140; 207; 329 (Tartarus); 259 (Olympus).

29 Alle Übersetzungen der lateinischen Zitate stammen von der Verfasserin. 
stehenden Kriegshandlungen retardiert, ${ }^{30}$ ist für den ,mythologischen` Teil noch ein anderer Aspekt entscheidend. Alle drei Mythologeme werden dem Rezipienten in extremer Verrätselung geboten. Schon die äußerst knappen Hinweise auf Minerva und Midas erschließen sich nur demjenigen, der den Verlauf des Mythos kennt. Ohne Vorkenntnisse unverständlich bleibt die in suspensa pelle $(2,258)$ liegende Anspielung auf die Häutung des Marsyas, zumal dieser nicht einmal mit seinem Namen, sondern lediglich als Apollinea victus testudine pastor $(2,257)$ eingeführt wird. Um die Verrätselung in all ihren Details zu entschlüsseln, ist eine gute Kenntnis der literarischen Prätexte erforderlich: Die Minerva-Anspielung wird erst nach der Lektüre von Ovids Fasti, die Marsyas- und Midas-Anspielungen nach der Lektüre seiner Metamorphosen verständlich. ${ }^{31}$ Der mythologische Katalog von In Eutropium erfordert also fundierte Literaturkenntnisse. Der Rückverweis auf Ovid ist dabei viel mehr als ein intellektuelles Spiel. Die Ovid-Reminiszenzen weisen Phrygien als literarische Landschaft aus und reklamieren sie als einen Teil der römischen Literaturtradition, in der Gestalten der antiken Literatur ihre Heimat haben: Es geht dem Dichter nicht primär um die Inhalte des Mythos, sondern darum, die Literatur- und Kulturtradition zu evozieren, in denen diese mythischen Begebenheiten tradiert werden. Indem der Dichter nun das reale Phrygien in einen Erinnerungsort ovidischer Mythen verwandelt, reklamiert er es als genuin römisches Gebiet ${ }^{32}$ - ein Aspekt, der die Plünderung dieser blühenden Kulturlandschaft durch die barbarischen Goten, die der Dichter im Anschluss an die Topothesie in dem Satz talem tum Phrygiam Geticis populatibus uri / permisere dei (2,274f.) lapidar zum Ausdruck bringt, umso illegitimer erscheinen lässt. Die Goten plündern nicht irgendeine Provinz im fernen Kleinasien, sie bedrohen die Kulturschätze der römischen Welt. Letztlich steht der Mythos also für römische Literatur, die römische Literatur für eine kulturelle Vormachtstellung, aus der sich die Gebietsansprüche ganz natürlich ergeben. Mit den Inhalten des eben erst zur Staatsreligion erklärten Christentums, die noch kein allgemeines Kulturgut sind und noch nicht einmal über eine allgemeine Akzeptanz verfügen, lässt sich eine ähnlich schlagkräftige Argumentation nicht führen.

\section{Der Mythos als Chiffre in politischen Diskursen}

Sehr viel häufiger noch als die Verknüpfung von Geographica mit mythischen Begebenheiten ist die direkte Gegenüberstellung von Protagonisten aus Claudians Gedichten mit mythologischen Figuren in Form von Synkriseis, wie sie die panegyrische

30 Vgl. H. Schweckendiek, Claudians Invektive gegen Eutrop (In Eutropium), Hildesheim u.a. 1992, 206.

31 Ov. met. 6,382-400 (Marsyas); fast. 6,693-710 (Minerva/Marsyas); met. 11,85-193 (Midas).

32 Eine ähnliche Funktion hat der Katalog griechischer Berge und Kultstätten in III Cons. Hon. 111-118. 
Theorie vorschreibt. ${ }^{33}$ Auch hier liefert der Mythos - anders als christliche Stoffe - in mehrfacher Hinsicht ein reichhaltiges Reservoir für die Herrscherlegitimation. Was die Auswahl der Stoffe angeht, ist zu beobachten, dass Claudian regelmäßig auf Mythen zurückgreift, die bereits vor seiner Zeit im politischen Diskurs Chiffren für Macht und Einflussnahme sind. Diese Chiffren werden innerhalb von Claudians dichterischem Werk mehrfach wiederholt und dadurch als feste Bilder etabliert: Olybrius und Probinus, Honorius und Arcadius und die beiden Theodosii erscheinen als Castor und Pollux: ${ }^{34}$ Das mythische Brüderpaar verkörpert bereits in früheren politischen Kontexten das Ideal der concordia und wird vor allem in der julisch-claudischen Dynastie verschiedentlich mit Thronerben in Beziehung gesetzt, z. B. dadurch, dass diese in gemeinsamen Tempeln verehrt werden. ${ }^{35}$

Relativ häufig sind in Claudians politischen Dichtungen Verweise auf Hercules, ${ }^{36}$ dessen Verbindung zur römischen Staatsmacht sich schon auf Münzprägungen des ersten vorchristlichen Jahrhunderts findet, der als Hercules Augustus oder Hercules Augusti für den Schutz des römischen Kaisers zuständig war, ${ }^{37}$ der in der Spätantike durch die Dynastie der Herculii ${ }^{38} \mathrm{zu}$ besonderer Prominenz aufstieg und auch in den Panegyrici Latini immer wieder als Referenz-Held herangezogen wird. ${ }^{39}$ Die Bezwingung der Giganten und anderer erdgeborener Ungeheuer schließlich, die bei Claudian wiederholt als Bild für die Überwindung externer Gegner verwendet wird, ${ }^{40}$ begegnet seit der spätarchaischen Zeit in Literatur und Kunst als Chiffre für den Sieg über die barbarische Bedrohung. ${ }^{41}$ Die verschiedenen Bilder vom Sturz des Phaethon und der Rettung der Welt durch Sol $^{42}$ implizieren nicht nur die verbreiteten allegorischen

33 Zum Begriff der Synkrisis, ihren Formen und ihrer Verwendung vgl. F. Focke, Synkrisis, Hermes 58 (1923), 327-368; L. Pernot, La rhétorique de l'eloge dans le monde gréco-romain, Bd. 2, Paris 1993, 690 698.

34 OlProb. 236-244; Gild. 213-222; IV Cons. Hon. 206-211.

35 Vgl. B. Poulsen, The Dioscuri and Ruler Ideology, SO 66 (1991), 119-146, bes. 123-125.

36 Ruf. 1,283-296; IV Cons. Hon. 132; 532-538; Stil. 1,143-147; Get. 377-379.

37 Vgl. M. Clauss, Kaiser und Gott. Herrscherkult im römischen Reich, München - Leipzig 2001, 281.

38 Z.B. Paneg. Lat. XI(III),3,2-3; vgl. W. Derichs, Herakles, Vorbild des Herrschers in der Antike, Diss. Köln 1950, 108f.; M. Mause, Die Darstellung des Kaisers in der lateinischen Panegyrik, Stuttgart 1994, 69; F. Kolb, Herrscherideologie in der Spätantike, Berlin 2001, 167-171.

39 Vgl. XII Panegyrici Latini, rec. brevique adnotatione critica instruxit R. A. B. Mynors, Oxford 1964, 294 (Index nominum s. v. Hercules). Auch in der nachantiken Herrscherlegitimation sind Verweise auf Hercules häufig, vgl. W. Sparn, Hercules Christianus. Mythographie und Theologie in der frühen Neuzeit, in: W. Killy (Hrsg.), Mythographie der frühen Neuzeit. Ihre Anwendung in den Künsten, Wiesbaden 1984, 73-107; J. Berger, Hercules - Held zwischen Tugend und Hybris. Ein europäischer Erinnerungsort der frühen Neuzeit?, in: I. Dingel, M. Schnettger (Hrsg.), Auf dem Weg nach Europa. Deutungen, Visionen, Wirklichkeiten, Göttingen 2010, 79-106; s. auch Meier in diesem Band.

40 III Cons. Hon. 152-162; IV Cons. Hon. 108; 532-538; Stil. 1,303-308; Get. 61-66; praef. VI Cons. Hon. 17-18.

41 F. Graf, A. Ley, s.v. Giganten, DNP 4 (1998), 1066-1069 (mit weiterführender Literatur).

42 IV Cons. Hon. 62-69; VI Cons. Hon. 165-177; 185-192. 
Deutungen des Mythos als kosmische Katastrophe, ${ }^{43}$ sondern auch die Gleichsetzung des Herrschers oder gar der Stadt Rom mit dem Sonnengott, der bis ins Jahr 325 auf Münzprägungen erscheint. ${ }^{44}$

Insbesondere diejenigen mythologischen Figuren, die in Claudians Panegyriken mehrfach zum Vergleich herangezogen werden, sind also durch Vorverwendungen in den verschiedensten politischen Kontexten und Medien fest etabliert, so dass ihr Erscheinen für die Rezipienten beinahe schon Signalwirkung gehabt haben dürfte. Dabei waren möglicherweise nicht einmal primär die Implikationen der ursprünglichen mythologischen Figur entscheidend, sondern ihre Rezeption und ihre Geläufigkeit in bestimmten politischen Kontexten: Wenn Claudian die weströmischen Würdenträger mit Hercules, den Dioskuren und Sol parallelisiert, macht er im Bewusstsein des Rezipienten hinter diesen mythischen Figuren immer frühere Herrscher sichtbar, die ebenfalls als Hercules, als Dioskuren oder als Sol gewürdigt worden waren. Die politische Botschaft, die sich mit bestimmten Gestalten und Ereignissen des Mythos verband, war offensichtlich so stark, dass sie Claudian bewogen hat, im Kontext seiner politischen Dichtungen an ihnen festzuhalten. Dies war ihm umso leichter möglich, als sämtliche mythologische Figuren, die in seinen Gedichten als Chiffren für politische Macht auftreten, nachweislich in christlichen Diskursen sanktioniert sind: Hercules wurde zwar von christlichen Autoren auf der einen Seite kritisiert, weil es ihm nicht gelungen sei, seine Leidenschaften $\mathrm{zu}$ besiegen, auch wird seine Unzucht verurteilt: ${ }^{45}$ Diese Seite seiner Persönlichkeit bleibt in Claudians Gedichten ausgespart. Andererseits gibt es Stimmen, die Hercules durchaus als tugendhaften Helden sehen, der am Scheideweg die richtige Wahl trifft. In den Stromata des Clemens von Alexandria erscheint er gar zusammen mit Alexander als Muster eines vernünftigen und göttlichen Herrschers. ${ }^{46}$ Boethius befasst sich in seiner Consolatio philosophiae ausführlich mit den Arbeiten des Hercules (cons. 4,7,13-35); als letzte Arbeit wird das Tragen des Himmelsgewölbes genannt. Mit ihr ist eine Aufforderung an die Tapferen verbunden, dem Beispiel des Hercules zu folgen und sich den Himmel zu verdienen. ${ }^{47}$ Wenn Claudian im ersten Buch von In Rufinum Stilichos Taten an den Taten des Hercules misst (1,283-296) oder in den Laudes Stilichonis Stilicho, der die politische Verantwortung bereitwillig übernimmt, mit Hercules vergleicht, der sich von Atlas das Himmelsgewölbe auf die Schultern laden lässt (1,143-147), dann mussten diese Vergleiche für christliche Rezipienten nicht unbedingt anstößig wirken, sondern konnten sogar positiv konnotiert sein. Die Gigantomachie ist ebenfalls ein

43 M. Hillgruber, Der Phaethon-Mythos als Gegenstand kosmologischer Spekulationen, Gym 102 (1995), 481-496.

44 Vgl. G. H. Halsberghe, The Cult of Sol Invictus, Leiden 1972, $169 \mathrm{f}$.

45 Angaben nach A. J. Malherbe, s.v. Herakles, RAC 14 (1988), 559-583, 574-581.

46 Clem. Al. Strom. 1,158,3.

47 Boeth. cons. 4,7,29-35: ultimus caelum labor inreflexo / sustulit collo pretiumque rursus / ultimi caelum meruit laboris. / Ite nunc, fortes, ubi celsa magni / ducit exempli via. Cur inertes / terga nudatis? superata tellus / sidera donat. Vgl. Schmitz (s. Anm. 22), $505 \mathrm{f}$. 
traditionelles Bild für politischen Umsturz. Sie ist im Herrscherlob fest etabliert, so dass nicht nur Claudian, sondern auch Eusebios in der Vita Constantini und Panegyriker mit einem nachgewiesenermaßen christlichen Hintergrund wie Sidonius Apollinaris und Coripp an ihr festhalten. ${ }^{48}$ Eine ähnlich positive Bewertung erfahren die Dioskuren: Bei Ennodius werden sie zusammen mit anderen mythischen Freundespaaren als Beispiele für Freundestreue angeführt, ${ }^{49}$ sie werden ferner mit Peter und Paul sowie mit Kosmas und Damian analogisiert und sogar unter die christlichen Märtyrer aufgenommen. ${ }^{50}$ Gerade die Konvergenz pagan-antiker und christlicher Deutungsmöglichkeiten prädestiniert mythische Figuren wie die Dioskuren, Hercules und die Giganten als panegyrische Vergleichsobjekte.

Am deutlichsten sind die Parallelen und Überlagerungen schließlich im Falle der Figur Apolls. Spätestens seit der Schlacht von Actium ist dieser Gott an die politischen Erfolge Roms gebunden. So beruft sich auch ein anonymer Panegyricus auf Konstantin auf den Schutzgott Apoll. ${ }^{51}$ Es ist daher nicht erstaunlich, dass Claudian Apoll mehrfach in Vergleichen heranzieht..$^{52}$ Besonders signifikant ist der Mythos von Apoll als Sieger über die Python-Schlange, den bereits Lucan in seiner Pharsalia auf zeitgeschichtliche Ereignisse bezieht. ${ }^{53}$ Claudian hat dieses Mythologem insgesamt dreimal verwendet: Im Panegyricus auf Olybrius und Probinus findet er sich innerhalb eines Vergleiches der von Proba angefertigten Konsulatsroben mit den Gewändern, die Latona für ihre Zwillinge Apollo und Diana webt (OlProb. 186-189), im Panegyricus auf das vierte Konsulat des Honorius in Verbindung mit dem Giganten-Mythos (IV Cons. Hon. 532-538). Die längste Version bietet die Praefatio zum ersten Buch von In Rufinum. Nachdem der Dichter den Mythos ausführlich referiert hat, beschließt er die Ausführungen mit einer Übertragung der mythischen Ereignisse auf die aktuelle Situation (Ruf. praef. 1,15-18):

\section{Nunc alio domini telis Pythone perempto convenit ad nostram sacra caterva lyram, qui stabilem servans Augustis fratribus orbem iustitia pacem, viribus arma regit.}

Nun, da ein neuer Python durch die Geschosse des Herrschers bezwungen, kommt die heilige Schar zum Klang meiner Lyra zusammen -

48 Euseb. Vit. Const. 1,5,1; Sidon. carm. 6,23-26; Coripp. Ioh. 1,451-459; 5,156f.; 6,658-660, vgl. J.-U. Andres, Das Göttliche in der Johannis des Corippus: Antike Götterwelt und christliche Wertvorstellung im Widerstreit?, Trier 1997, 23-27.

49 Ennod. Epist. 1,9: nobis, si placet in novellum usum maiorum exempla revocare, potius Pyladis et Orestis, Nisi et Euryali, Pollucis et Castoris, si nihil his clandestinorum actuum decerpit obscenitas, convenit gratiae meminisse vel fidei.

50 W. Kraus, s.v. Dioskuren, RAC 3 (1957), 1122-1138, 1333-1138.

51 Paneg. Lat. VI(VIII),21,4-22,1.

52 IV Cons. Hon. 132-136; Stil. 3,58-62; VI Cons. Hon. 26-38.

53 Lucan. 7,148. 
des Herrschers, der dauerhaft den Erdkreis bewahrt für die Kaiser-Brüder und mit Gerechtigkeit den Frieden wahrt, mit Stärke die Waffen schwingt.

Auffällig an dieser Übertragung ist eine gewisse Asymmetrie: Rufin erscheint als „neuer Python“ (alio Pythone, 15), als Reinkarnation des mythischen Untiers. Sein Bezwinger Stilicho hingegen ist kein ,neuer Apoll‘, sondern wird in seiner aktuellen politischen Funktion als dominus, der als Vormund für Honorius und Arcadius (servans Augustis fratribus orbem, 17) die Welt im Frieden wie im Krieg lenkt, eingeführt. Bei näherer Betrachtung erweist sich diese Asymmetrie als Kunstgriff: Zum einen markiert die unmittelbare Identifikation Rufins mit der Python-Schlange die Größe und Irrationalität der Bedrohung, die von dem oströmischen praefectus praetorio ausgeht. Der Dichter bereitet so schon hier Rufins Diffamierung als Ziehsohn der Furie Allecto vor, mit der er das erste Buch von In Rufinum eröffnen wird. Zum anderen lässt sich, was den symbolischen Gehalt angeht, in die Apollo-Python-Geschichte sehr viel leichter noch als in andere Mythen ein christlicher Subtext hineinlesen. Wie Isabella Gualandri gezeigt hat, ${ }^{54}$ weist die Praefatio zum ersten Rufin-Buch auffällige Übereinstimmungen mit Eusebs Vita Constantini auf. Dort wird berichtet, dass Konstantin über dem Eingang des Palasts ein Bildnis von sich als Schlangenbezwinger anbringen ließ; die Schlange steht nach Eusebs eigener Interpretation für den Dämon, der die Kirche angegriffen hat. ${ }^{55}$ Spätere Herrscher machten sich diese Ikonographie ebenfalls $\mathrm{zu}$ eigen, so dass für die christlichen Rezipienten von Claudians Dichtungen in der Apollo-Python-Episode ein christlicher Subtext mitschwingen konnte. ${ }^{56}$ In der Gestalt der Python-Schlange repräsentiert Rufin somit das Dämonische und das ultimativ Böse. Stilicho hingegen, der dominus, wird zu einem neuen Konstantin: Der mythische Drachentöter Apoll avanciert also zunächst zu einem christlichen Herrscher und wird schließlich zu Stilicho, der das Erbe des christianissimus imperator Theodosius vollkommen zu Recht antritt.

\section{Der Mythos als Grundlage für panegyrische Überbietung}

Claudian begnügt sich in vielen Fällen jedoch nicht damit, die Taten und Verhaltensweisen seiner Protagonisten mit den Taten und Verhaltensweisen mythischer Figuren gleichzusetzen. Die Synkrisis mit einer mythischen Figur bildet für ihn, wie

54 Vgl. I. Gualandri, Alio ... Pythone perempto: Tracce „costantiniane“ nell' In Rufinum di Claudiano, in: P. Arduini (Hrsg.), Studi offerti ad A. Perutelli, Bd. 2, Rom 2008, 71-80, 72-75.

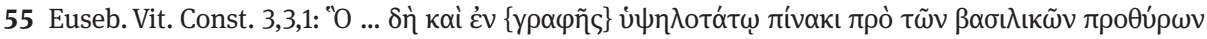

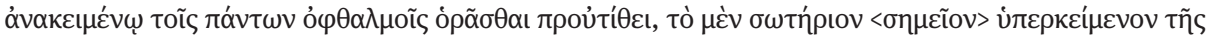

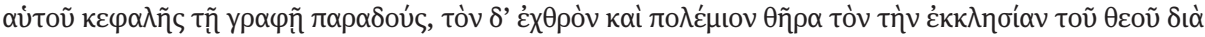

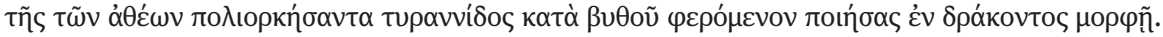

56 Vgl. Gualandri (s. Anm. 54), 76. 
verschiedentlich bemerkt wurde, ${ }^{57}$ oftmals nur den Ausgangspunkt für eine steigernde Überbietung - auch dies ist ein Vorteil, den der Mythos gegenüber biblischen Stoffen hat. Insbesondere Stilicho wird konsequent als Persönlichkeit gezeigt, die in ihren Handlungen den Figuren des Mythos überlegen ist. Siegmar Döpp weist darauf hin, dass der „panegyrische Topos der Überbietung“ bereits in den Silven des Statius angelegt und überhaupt „in der Panegyrik besonders beliebt“ gewesen sei. ${ }^{58}$ Claudian setzt den Typus des überbietenden Vergleichs allerdings sehr viel konsequenter und elaborierter ein als seine Vorgänger. Er bedient sich dabei häufig der „synkrisis analitica“, in der, wie Isabella Gualandri zeigt, einzelne Aspekte in minutiösen Vergleichen herausgearbeitet werden, um beim Rezipienten den Eindruck einer Objektivität zu erzeugen. ${ }^{59}$ Überbietungen des Mythos sind bei Claudian nicht nur ungleich häufiger als bei früheren Panegyrikern, „der mythologische Vergleich hat bei Claudian den Gipfel seiner Entwertung erreicht“ “. ${ }^{60}$ Das vielzitierte Diktum von der superata vetustas, ${ }^{61}$ die angesichts der Großtaten Stilichos schweigen soll, zeigt, dass der Dichter sich seiner Strategie durchaus bewusst ist und sie auch seinem Rezipienten bewusst machen möchte.

Die einfachste Form der Überbietung besteht darin, den Gepriesenen und sein Verhalten mit dem Verhalten einer oder mehrerer mythologischer Figuren zu konfrontieren, um ihn abschließend als qualitativ oder quantitativ überlegen zu erweisen. So dient etwa im Bellum Geticum eine Abfolge von mythischen Begebenheiten dem Dichter dazu, die Ankunft Stilichos in dem von Goten bedrohten Italien zu bewerten (Get. 438-449):

creditur Herculeis lucem renovasse lacertis

femina dilecti fatis impensa mariti;

et iuvenem spretae laniatum fraude novercae

non sine Circaeis Latonia reddidit herbis;

Cretaque, si verax narratur fabula, vidit

Minoum rupto puerum prodire sepulchro, quem senior vates avium clangore repertum gramine restituit; mirae nam munere sortis

dulcia mella necem, vitam dedit horridus anguis:

at tuus adventus non unum corpus ab umbris,

sed tot communi populos sub morte iacentes

totaque Tartareis e faucibus oppida traxit.

57 Z.B. Fargues (s. Anm. 5), 211f.; Döpp (s. Anm. 1), 35 f.

58 Döpp (s. Anm. 1), 36. Zur Überbeitung der mythologischen Vergangenheit durch die christliche Gegenwart s. Accorinti in diesem Band.

59 I. Gualandri, Aspetti della synkrisis nella poesia latina tardoantica: Claudiano, in: G. Hinojo Andrés, J. C. Fernández Corte (Hrsg.), Munus quaesitum meritis. Homenaje a Carmen Codoñer, Salamanca 2007, 445-453, 446.

60 R. Herzog, Die allegorische Dichtkunst des Prudentius, München 1966 (Zetemata 42), 131.

61 Claud. Ruf. 1,283: taceat superata vetustas; ähnlich bereits OlProb. 197 f.: talem nulla refert antiquis pagina libris / nec Latiae cecinere tubae nec Graia vetustas. 
Man glaubt, dass durch Hercules' Arme die Frau das Licht der Welt erneut erblickt hat, die sich geopfert hat für das Schicksal ihres geliebten Mannes; und den jungen Mann, der zerrissen worden war durch den Betrug der verschmähten Stiefmutter, gab (aber nicht ohne die Kräuter der Kirke) Latonia dem Leben zurück. Und Kreta, wenn die Geschichte, die man erzählt, tatsächlich wahr ist, sah den Sohn des Minos aus dem aufgebrochenen Grab hervortreten - ihn, den der greise Seher durch Vogelgeschrei fand und mit Heilkraut ins Leben zurückholte: Denn durch das Geschenk eines wundersamen Schicksals gab süßer Honig ihm den Tod, gab das Leben ihm eine schreckliche Schlange. Doch deine Ankunft hat nicht einen Toten aus dem Schattenreich erlöst, sondern so viele Völker, die unter einem gemeinsamen Tod dalagen, und so viele Städte aus dem Rachen des Tartarus befreit.

Grundlage für die Gegenüberstellung ist ein mythologisches Trikolon aus Hercules, Diana und dem kaum bekannten und namentlich nicht genannten Polyidus. Der Dichter ruft zunächst in überaus gelehrter Verknappung, aber mit einer stark emotionalen Färbung seiner Darstellung, die Taten dieser Personen in Erinnerung: Hercules holte Alcestis aus der Unterwelt zurück, „die sich für das Schicksal ihres geliebten Mannes geopfert hat“ (dilecti fatis impensa mariti, 439), Diana den Hippolytus, „der durch den Betrug der verschmähten Stiefmutter zerrissen worden war“ (spretae laniatum fraude novercae, 440), Polyidus den Glaucus, „,dem durch das Geschenk eines wundersamen Schicksals süßer Honig den Tod und eine schreckliche Schlange das Leben gab" (mirae nam munere sortis / dulcia mella necem, vitam dedit horridus anguis, $445 \mathrm{f}$.). ${ }^{62}$ Diese Verweise auf die bewegenden Schicksale der Geretteten werten einerseits die Leistungen der mythischen Unterweltsfahrer auf und inszenieren Stilichos Mission gegen die Goten als eine Art Katabasis, zumal die Goten im Folgenden sogar explizit mit dem Rachen des Tartarus (Tartareis faucibus, 449) gleichgesetzt werden. Andererseits meldet der Dichter bereits im Laufe der Erzählung durch die Formulierungen creditur (438) und si verax narratur fabula (442) Zweifel an der Glaubwürdigkeit der Überlieferung an und wertet Dianas Leistung durch den Hinweis ab, dass sie ohne Kirkes Zauberkräuter (non sine Circaeis herbis, 440) nicht hätte vollbracht werden können. Durch at scharf gegen die mythologische Überlieferung abgesetzt ist schließlich die Tat des Stilicho, wobei der Dichter die Emotionalität der Mythen mit dem Aspekt der schieren Masse aussticht: Stilichos Ankunft habe nicht nur eine einzige Person (non unum corpus, 447), sondern ganz Völkerschaften (tot communi populos sub morte iacentes, 448) noch vor ihrem Ableben dem sicheren Tod entrissen und zahlreiche Städte vor dem Untergang gerettet (totaque Tartareis e faucibus oppida traxit, 449). Die prosaische Ausdrucksweise des Stilicho-Abschnittes, aus der nur die Formulierung Tartareis e faucibus herausfällt, desavouiert den Mythos zusätzlich: Wäh-

62 Polyidus wurde von Minos ausgeschickt, um dessen verschwundenen Sohn Glaucus aufzuspüren. Er fand Glaucus in einem Weinkeller vor, ertrunken in einem Honigfass, und wurde von Minos mit dem Auftrag, den Sohn wieder lebendig zu machen, in dem Weinkeller eingesperrt. Als eine Schlange in den Keller eindrang, wurde sie von Polyidus getötet. Daraufhin erschien eine zweite Schlange, die ein Heilkraut mitbrachte, das die getötete Schlange wieder zum Leben erweckte. Mit diesem Heilkraut machte Polyidus dann den Minos-Sohn wieder lebendig. Der sehr entlegene Mythos ist bei Apollod. Bibl. 3,3,1-2 und (in einer Variation für Aesculapius anstelle von Polyidus) bei Hyg. Fab. 136 überliefert. 
rend dieser seinen Effekt aus seiner Emotionalität und aus der kunstvollen poetischen Darstellung zieht, wirken Stilichos Leistungen per se.

Es kommt jedoch noch etwas hinzu. Überbietende Synkriseis wie diese sind paganen wie christlichen Rezipienten, wie gesagt, aus der panegyrischen Tradition geläufig. Speziell der Vergleich mit mythischen Unterweltsfahrern ist sogar mit einer nahezu identischen Motivik und Gedankenführung in einer Rede des Libanius an Theodosius zu finden, an die sich manche von Claudians Rezipienten noch erinnert haben mögen (Libanius or. 20,8 Bd. 2, 424 f. Foerster):

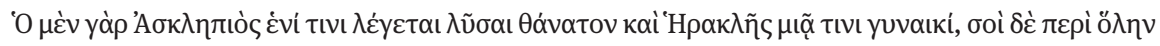

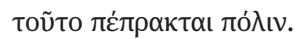

Asklepios soll einen Mann vom Tod erlöst haben und Herakles eine Frau - du aber hast dies hinsichtlich der ganzen Stadt vollbracht! ${ }^{63}$

Motiv und Durchführung des Vergleiches sind so ähnlich, dass der Rekurs unmittelbar erkennbar ist, auch wenn die Reihenfolge vertauscht ist, der Verweis auf Hippolytus fehlt und Asklepios an der Stelle des Polyidus steht: Hier zeigt sich noch einmal, dass es dem Dichter nicht um die Mythologeme an sich geht, sondern wiederum um die implizite Gleichsetzung Stilichos mit dem christianissimus imperator Theodosius.

Aber auch aus christlicher Sicht ist der Einsatz von überbietenden Synkriseis wie der eben besprochenen noch aus anderen Gründen nicht nur unanstößig, sondern sogar begrüßenswert: Einmal deswegen, weil die Demontage der mythologischen Figuren und Ereignisse zur Schwächung des paganen Mythos beiträgt und gerade die paganen Jenseitsmythen den christlichen Autoren schon lange ein Dorn im Auge waren, ${ }^{64}$ zum anderen deswegen, weil es sich bei der Synkrisis auch um eine christliche Argumentationsform handelt, mit der schon Origenes in seiner Schrift Contra Celsum die Überlegenheit Josephs über den griechischen Helden Bellerophon nachgewiesen hatte. ${ }^{65}$ Wenn Claudian die mythologische Synkrisis als Mittel der Überbietung einsetzt, rückt er also den Herrscher in die Nähe biblischer Figuren: Seine Überlegenheit über Figuren des Mythos hat Stilicho nicht nur mit Theodosius, sondern auch mit Figuren wie Joseph gemeinsam.

\section{Die Fiktionalität der Mythos}

Eine weitere Strategie der panegyrischen Überbietung, die in Claudians Gedichten in immer neuen Variationen zur Anwendung kommt, besteht darin, die Fiktionalität mythischer Begebenheiten gegen den Wahrheitsgehalt der zeitgeschichtlichen Ereignisse auszuspielen. Die Kritik am mangelnden Wahrheitsgehalt des Mythos hat in

63 Die Stelle ist verzeichnet bei H. Schroff (Hrsg.), Claudians Gedicht vom Gotenkrieg, Berlin 1927, 64. Ein ähnliches Bild findet sich auch bei Libanius or. 13,42 Bd. 2, 77 f. Foerster.

64 Vgl. Schmitz (s. Anm. 22), 503 f.

65 Origenes Cels. 4,46; vgl. Schmitz (s. Anm. 22), 503. 
der Antike eine lange, bis auf die ,lügenden Musen` in Hesiods Theogonie (27f.) zurückreichende Tradition, die vor allem im philosophischen Schrifttum kultiviert wurde und den christlichen Schriftstellern zahlreiche Anknüpfungspunkte bot. ${ }^{66}$ Augustin gelten Stoffe der Aeneis als poetica figmenta (civ. 18,15) oder als poetica vanitas (civ. 19,12), „den mythischen Erfindungen der Dichter setzt er den wahrhaftigen christlichen Gott entgegen“, ${ }^{67}$ und das christliche Verdikt setzt sich bis zu den figmenta poetarum des Mittelalters hinein fort, die man in allegorischer Lesart gleichwohl weitertradierte. ${ }^{68}$

Auf der anderen Seite ist es auch in der panegyrischen Tradition üblich, sich vom Mythos zu distanzieren, indem man ihn als „Tradition“ oder als „Bericht der Dichter“ markiert; ${ }^{69}$ die Normativität des Mythos steht dabei jedoch außer Frage. In Claudians Dichtung treffen sich diese Argumentationsmuster. Verschiedentlich distanziert sich der Erzähler durch unpersönliche Wendungen wie cantatur (Eutr. 1,290), einschränkende Formulierungen fabula, seu verum, canitur (Stil. 3,231) oder, wie in dem oben besprochenen Beispiel, durch si verax narratur fabula (Get. 442) von seinen mythologischen Gegenständen; einmal schiebt er die Fiktionen den ,alles übersteigernden Musen“ (augentibus omnia Musis: VI Cons. Hon. 475) zu. Die ausführlichste und komplexeste Konfrontation von mythischer Fiktion und panegyrischer ,Realität‘ findet sich zu Beginn des Bellum Geticum. ${ }^{70}$ Dieses Gedicht setzt - einigermaßen überraschend $^{71}$ - mit einem ausführlichen Referat der Leistungen des Tiphys, des Steuermanns der Argo, bei der Durchfahrt durch die Symplegaden ein. Tiphys’ herausragende Leistung wird allerdings bereits in den ersten Versen wieder relativiert: Die Symplegaden-Durchfahrt gelang nur mit göttlicher Beteiligung (post numina, 4) und mit einem - wenngleich nur kleinen - Schaden für das Schiff (tenui damno, 5). ${ }^{72}$ Schon in Vers 6 wird der Mythos durch ein fertur in seiner Glaubwürdigkeit grundsätzlich in

66 Vgl. M. Fuhrmann, Die antiken Mythen im christlich-heidnischen Weltanschauungskampf der Spätantike, Antike und Abendland 36 (1990), 138-151, 141 f.; Schmitz (s. Anm. 22), 492 - 494 (auch zum Folgenden).

67 Schmitz (s. Anm. 22), 493.

68 Vgl. L. Gompf, Figmenta poetarum, in: A. Önnerfors u.a. (Hrsg.), Literatur und Sprache im europäischen Mittelalter. Festschrift für K. Langosch, Darmstadt 1973, 53-62.

69 Vgl. Pernot (s. Anm. 33), 763.

$70 \mathrm{Zu}$ der gesamten Stelle ausführlich C. Schindler, Claudians Argonautica. Zur Darstellung und Funktion des Mythos zu Beginn des Epos De bello Getico (1-35), in: A. Harder, M. Cuypers (Hrsg.), Beginning from Apollo. Studies in Apollonius Rhodius and the Argonautic Tradition, Leuven - Paris Dudley, MA 2005, 107-123.

71 Vgl. I. Gualandri, „Solus post numina Tiphys“.Variazioni claudianee sul tema della nave Argo (Bell. Get. 1-35), in: L. Castagna, Ch. Riboldi (Hrsg.), Amicitiae templa serena: Studi in onore di Giuseppe Aricáo, Bd. 1, Mailand 2008, 753-776, 755.

72 Der Versuch von Gualandri (s. Anm. 71), 761-764, diese Einschränkungen mit der aktuellen Politik Stilichos abzugleichen, scheint mir in der panegyrischen Situation, in der es ja um eine konsequente Überhöhung des Gepriesenen geht, nicht ganz treffend. 
Frage gestellt und in Vers 10 mit einer rhetorischen Frage vollends zurückgestuft (Get. 11-14): ${ }^{73}$

\section{[...] quod si ardua Tiphyn \\ navis ob innocuae meritum sic gloria vexit, quae tibi pro tanti pulso discrimine regni \\ sufficient laudes, Stilicho?}

Wenn nun stolzer Ruhm den Tiphys dafür in den Himmel hob, dass er ein Schiff unversehrt bewahrte, welche Ehrungen werden dann für dich dafür, dass du die Gefahr von einem so großen Reich abgewehrt hast, hinreichend sein, Stilicho?

Hier lenkt der Dichter unter Verwendung der alten Metapher vom „Staatsschiff“74 von der realen Argo auf den römischen Staat über, um Stilichos Überlegenheit zu erweisen. Seinen poetischen Vorgängern wirft er zugleich vor, durch übermäßiges Lob mythischer Großtaten falsche Maßstäbe gesetzt zu haben, die es ihm schwer machten, den wahren Helden Stilicho angemessen zu loben: Wenn schon Tiphys unsterblichen Ruhm dafür erntete, ein einziges (reales) Schiff durch die Symplegaden manövriert zu haben, so führt der Dichter aus, welche Würdigungen sind dann noch den Leistungen Stilichos angemessen, der ja das Staats-Schiff ,Römisches Reich` vor dem Untergang gerettet habe? Im Folgenden wird die panegyrische Aussage noch weiter gesteigert, indem der Dichter die Zweifel an dem Wahrheitsgehalt des Mythos, die er in der Symplegaden-Episode durch fertur bereits angedeutet hatte, konkretisiert: Die Berichte vom Argonautenzug zögen ihre Wirkung vor allem aus den Aufbauschungen der Dichter (Get. 14-27):

\section{[...] licet omnia vates}

in maius celebrata ferant ipsamque secandis

Argois trabibus iactent sudasse Minervam

nec nemoris muti iunxisse carentia sensu

robora, sed caeso Tomarii Iovis augure luco

arbore praesaga tabulas animasse loquaces;

plurima sed quamvis variis miracula monstris

ingeminent teneras vincturo carmine mentes,

Harpyiasque truces insopitisque refusum tractibus aurati custodem velleris anguem et iuga taurorum rapidis ambusta favillis et virides galeis sulcos fetasque novales

Martis et in segetem crescentia semina belli:

nil veris aequale dabunt. [...]

Mögen auch die Dichter alles, was sie feiern, größer machen als es ist, und stolz verkünden, dass Minerva selbst beim Schneiden der Argo-Planken Schweiß vergossen und nicht gefühlloses Eichenholz eines stummen Hains zusammengefügt, sondern den weissagenden Hain des Tomari-

73 Vgl. Herzog (s. Anm. 60), 132.

74 Vgl. I. Gualandri, Aspetti della tecnica compositiva in Claudiano, Mailand - Varese 1968, 66. 
schen Jupiter gefällt und mit dem schicksalskündenden Baum die Schiffsplanken beseelt habe, dass sie sprechen konnten: Mögen sie auch noch so viele Wunder und verschiedene Monster aufhäufen, die in einem epischen Gedicht leichtgläubige Gemüter zu fesseln vermögen, trotzige Harpyien, eine Schlange, die sich in niemals schlafenden Windungen als Wächterin eines Goldenen Vlieses rekelt, Stiergespanne, ringsum angesengt von glühender Asche, Ackerfurchen, grün von Helmen und die menschenschwangere Areswiese, und zu einer Saat aufkeimende Samen des Krieges: Sie werden nichts aufbieten können, das der Wahrheit ebenbürtig ist.

Auch wenn die Dichter alles aufböten, um die Prominenz des Mythos zu steigern Minervas göttliche Hilfe beim Bau der Argo, der sprechende Kielbalken aus dem Holz der Dodonäischen Eiche, verschiedene Monster wie die Harpyien, eine niemals schlafende Schlange, feuerschnaubende Stiere und aus dem Boden wachsende Erdgeborene: Gegen die wahren Leistungen Stilichos haben sie keine Chance: nil veris aequale dabunt (27). Der Dichter stellt hier das mythologische Dichten an sich in Frage und verbannt es auf eine niedrigere Kulturstufe, indem er durch die Formulierung teneras vincturo carmine mentes (21) die Rezipienten mythologischer Dichtungen als unbedarfte Kinder entlarvt. Durch den ,mythologischen Beginn' des Bellum Geticum wird die Erwartung des Rezipienten bewusst getäuscht: Der Mythos von der Argo, der in der früheren römischen Literatur, etwa in den Argonautica des Valerius Flaccus, als mythische Chiffre für historische Großtaten verwendet worden war, ${ }^{75}$ erweist sich in dem spätantiken Kontext als gänzlich ungeeignet. Dass wir uns nicht in einem ProsaPanegyricus, sondern in einem formal als Epos ausgewiesenen Text befinden, verschärft die Abgrenzung: Der Dichter markiert hier sehr klar, dass er bei allem formalen Traditionalismus nicht gewillt ist, an gängige episch-mythologische Traditionen anzuknüpfen, sondern im Gegenteil einen radikalen Bruch zu provozieren bereit ist. Der Mythos ist zwar vielleicht noch ein normativer Referenzpunkt für die gebildeten Rezipienten Claudians, um die Leistungen Stilichos besser einordnen zu können: Er muss aber den Großtaten der spätantiken Elite ebenso weichen, wie das mythologische Epos den politischen Dichtungen Claudians Platz machen muss. Die programmatische Aussage an der Spitze des Gedichts lässt sich außerdem auf alle weiteren Mythologica im Bellum Geticum (und vielleicht sogar in allen weiteren Gedichten Claudians) übertragen: Mythische Darstellungen sind stets mit dem Makel der Fiktionalität behaftet.

\section{Mythenkritik und Destruktion „klassischer“ Mythen in Claudians politischen Dichtungen}

Dass Claudian in seinen Panegyriken insgesamt nicht eine nostalgische Wiederbelebung des Mythos, sondern sogar eine dezidierte Abkehr von den mythischen Stoffen

75 Vgl. E. Burck, Die Argonautica des Valerius Flaccus, in: ders. (Hrsg.), Das römische Epos, Darmstadt 1979, 208-253, 211; Schindler (s. Anm. 70), 120. 
anstrebt, zeigt sich besonders deutlich an den Stellen, an denen er nicht nur die Überlegenheit der Protagonisten über die mythischen Helden erweist und auf die Fiktionalität des Mythos abhebt, sondern einen mythischen Prätext, der in der allgemeinen Wahrnehmung als positiv oder zumindest als neutral wahrgenommen wird, durch eine Umdeutung ins Negative in Frage stellt. Dies geschieht zum Teil implizit, wie zum Beispiel im ersten Buch der Laudes Stilichonis (1,318-324):

non ego dilectu, Tyrii sed vomere Cadmi

tam subitas acies concepto dente draconis

exiluisse reor: Dircaeis qualis in arvis

messis cum proprio mox bellatura colono

cognatos strinxit gladios, cum semine iacto

terrigenae galea matrem nascente ferirent

armifer et viridi floreret milite sulcus.

\begin{abstract}
Nicht, so glaube ich, durch Aushebung, sondern aus der Furche der Pflugschar des tyrischen Kadmos sind aus Drachenzahn so plötzlich Schlachtreihen hervorgesprungen. Wie in den dirkäischen Gefilden die Saat, die bald mit ihrem eigenen Sämann Krieg führen sollte, die blutsverwandten Schwerter zückte, als nach der Aussaat Erdgeborene mit entstehendem Helm ihre Mutter schlugen und von frisch emporgesprossenem Soldaten die waffentragende Furche prangte.
\end{abstract}

Ausgangspunkt für den Vergleich ist die Schnelligkeit, mit der es Stilicho gelang, die Truppen für den Kampf gegen die Bedrohungen aus dem Osten und dem Westen zu sammeln. Diese unglaubliche Geschwindigkeit deute, so die persönliche Auffassung des Dichters, nicht auf eine normale Truppenaushebung (dilectus, 1,318) hin, sondern darauf, dass die Soldaten der thebanischen Drachensaat des Kadmos (vomere Cadmi, 1,318) entsprungen seien - ein Bild, das anschließend in sieben Versen breit ausgemalt wird. Gerade die Tatsache, dass dieses Bild eher märchenhaft und auch ohne weiteren Hinweis des Dichters als fiktional zu identifizieren ist, überhöht Stilichos Leistung: Seine realen Erfolge sind so verblüffend, dass der Dichter nur an ein mythisches Mirakel glauben kann. Der Verweis auf die Gründung Thebens, der in der KadmosGeschichte mitschwingt, könnte zudem die auf die ,Neugründung' Roms durch Stilicho hinweisen, die Claudian am Schluss des ersten Buches explizit formuliert hat. ${ }^{76}$

Auch hier bedient sich der Dichter also zunächst der Normativität des Mythos, um seinen Rezipienten die Größe von Stilichos Erfolgen vor Augen zu führen. Doch davon abgesehen wird schnell deutlich, dass die Geschwindigkeit, mit der die Truppen parat stehen, der einzige Punkt ist, in dem Kadmos' und Stilichos Heer sich gleichen. Denn Kadmos' Sparten sind, wie der Dichter im Folgenden ausführt, eine „Saat, die bald mit ihrem eigenen Sämann Krieg führen sollte“, messis cum proprio mox bellatura colono (1,321), sie ziehen „blutsverwandte Schwerter“, cognatos gladios (1,322), mit denen sie sich gegenseitig bekriegen und sogar auf ihre eigene Mutter einschlagen: cum semine iacto / terrigenae galea matrem nascente ferirent (1,323f.). Das schnelle Emporwachsen

76 Vgl. Claud. Stil. 1,370-385. 
der thebanischen Sparten ist somit vollkommen sinnlos, da es zu einem blutigen Bruderkrieg führt, bei dem es, wie Claudians Publikum bekannt gewesen sein dürfte, nur wenige Überlebende gab. Die Variante des Mythos, dass die Sparten auch gegen Kadmos kämpfen, ist ungewöhnlich und vor Claudian nicht belegt; ${ }^{77}$ er hat sie möglicherweise selbst erfunden, um die Situation noch weiter zuzuspitzen. Die Wendung cognatos gladios $(1,322)$ zitiert überdies die Wendung cognatas acies am Beginn von Lucans Pharsalia $(1,4)$ und ruft dadurch zugleich die Erinnerung an die römischen Bürgerkriege des ersten vorchristlichen Jahrhunderts auf - zumal bereits Lucan den Mythos von Kadmos' Drachensaat (allerdings innerhalb des Jason-Mythos) als Bild für den römischen Bürgerkrieg herangezogen hat (Lucan. 4,549-556); zwischen diesem Bild und Claudians Schilderung lassen sich zahlreiche Übereinstimmungen feststellen. ${ }^{78}$

Stilicho hingegen führt einen legitimen Krieg, den er vorher vom Senat hat genehmigen lassen: non ante fretis exercitus astitit ultor / ordine quam prisco censeret bella senatus (Stil. 1,326f.). Gegenüber dieser ausgefeilten und von der Tradition sanktionierten Rechtlichkeit, der Honorius' Heermeister sich fügt, erscheint der thebanische Mythos von den einander bekriegenden Sparten primitiv: Er gehört einer Epoche an, die im ausgehenden vierten Jahrhundert längst überwunden ist, wie Claudian selbst es im Bellum Gildonicum den älteren Theodosius formulieren lässt: ne consanguineis certetur comminus armis, / ne, precor. haec trucibus Thebis, haec digna Mycenis (286f.). Bruderkriege sind Thebens und Mykenes, aber nicht Roms würdig. Den Gepriesenen zeichnet also aus, dass er die positiven Aspekte des Mythos tradiert, die negativen hingegen überwindet.

Sogar noch einen Schritt weiter geht Claudian im Panegyricus auf das sechste Konsulat des Honorius. Er rekapituliert hier die Aggressionen und Usurpationen von Alarich und Gildo gegen Honorius' Vater Theodosius; doch nun könne der Vater sich seines gerechtfertigten Zornes erinnern und genießen, dass beide Aggressoren ihre gerechte Strafe erhalten hätten (VI Cons. Hon. 113-121):

\footnotetext{
ense Thyestiadae poenas exegit Orestes, sed mixtum pietate nefas dubitandaque caedis gloria materno laudem cum crimine pensat; pavit Iuleos inviso sanguine Manes Augustus, sed falsa pii praeconia sumpsit in luctum patriae civili strage parentans: at tibi causa patris rerum coniuncta saluti bellorum duplicat laurus, isdemque tropaeis reddita libertas orbi, vindicta parenti.
}

Mit dem Schwert vollstreckte Orestes die Strafe über den Thyestes-Sohn, doch seinem Frevel war die Erfüllung der Sohnespflicht beigemischt und zweifelhaft der Ruhm für die Mordtat, wenn er

77 Vgl. U. Keudel, Poetische Vorläufer und Vorbilder in Claudians De consulatu Stilichonis. Imitationskommentar, Göttingen 1979 (Hypomnemata 26), $56 \mathrm{f}$.

78 Vgl. Keudel (s. Anm. 77), 57. 
mit einem Verbrechen an der Mutter den Ruhm wägt. Es nährte Augustus die Manen Caesars mit dem Blut seiner Feinde, doch falsch tat er seinen ehrfurchtsvollen Respekt kund, indem er Sühne übte mit Bürgerblut zur Trauer des Vaterlandes. Doch dir verdoppelt die Sache des Vaters, verbunden mit Rettung des Staates, den Kriegslorbeer, und durch dieselben Siegeszeichen wurde dem Erdkreis die Freiheit zurückgegeben und Rache dem Vater.

An dieser Stelle illustrieren zwei Beispiele, dass es dem Sohn nicht selten zufällt, für seinen ermordeten Vater Rache nehmen zu müssen: Der Dichter nennt zuerst Orestes, der seine Mutter Klytaimnestra erschlug, um den Mord an seinem Vater zu rächen, dann Octavian (Augustus, 117), der mit den Bürgerkriegen die Ermordung seines Adoptivvaters sühnen wollte. Die Verbindung von Orestes und Augustus ist traditionell: Michael Dewar vermutet, dass Claudian hier ein Legitimationsmuster der augusteischen Propaganda aufnimmt, mit dem Orestes' Muttermord Octavians grausames Vorgehen gegen die Caesar-Mörder rechtfertigte. ${ }^{79}$ Claudian benutzt die beiden Bilder jedoch nicht, wie man es vielleicht erwarten könnte, um Honorius in die Traditionslinie Orestes - Octavian einzureihen. Im Gegenteil: Orestes habe sich, so führt er aus, mit dem Ruhm, seinen Vater gerächt zu haben, zugleich die Bürde des Muttermordes aufgeladen, seine Tat sei somit ein mit Sohnespflicht vermischter Frevel, der Ruhm, den er für den Mord davontrage, zweifelhaft: mixtum pietate nefas dubitandaque caedis / gloria (114f.). Noch vernichtender fällt die Kritik an Octavian aus: Dieser habe unter dem Deckmantel einer falschen pietas gehandelt (falsa pii praeconia sumpsit, 117) und die Welt in einen gefährlichen Bürgerkrieg gestürzt: in luctum patriae civili strage parentans (118). Gegen diese beiden Negativ-Exempla wird Honorius positiv abgesetzt: Er habe die Angelegenheiten, die seinen Vater betrafen, mit dem allgemeinen Wohl verbunden und so seinen Kriegsruhm verdoppelt: at tibi causa patris rerum coniuncta saluti / bellorum duplicat laurus (119f.), mit der Rache für den Vater sei die Befreiung des Erdkreises einhergegangen: reddita libertas orbi, vindicta parenti (121). An die Stelle von nefas, crimen und einer dubitanda gloria, von invisus sanguis, luctus und civilis strages in den Beispielen von Orestes und Octavian treten auf Seiten des Honorius die juristisch und ethisch einwandfreie causa patris, die salus rerum und schließlich libertas. Die Rechtlichkeit von Stilichos Handeln wird gegen die Primitivität des Mythos abgegrenzt; Octavian, der mythenkonform handelte, wird ebenfalls politische Unreife attestiert. In Honorius' Handeln hingegen sind persönliche Emotionen und Allgemeinwohl nicht mehr diametral entgegengesetzt, sondern bilden eine Einheit: Der Herrscher überwindet die Unzulänglichkeiten und Fehler nicht nur seines mythischen, sondern auch seines politischen Vorgängers.

79 M. Dewar, Claudian, Panegyricus de sexto consulatu Honorii Augusti, Oxford 1996, 138. Grundlegend zu Orestes und Augustus T. Hölscher, Augustus and Orestes, Travaux du Centre d'archéologie méditerranéenne de l'Académie Polonaise des sciences 30. Études et Traveaux 15 (1990), 164-168; zuletzt S. Tilg, Augustus and Orestes. Two Literary Clues, CQ 58 (2008), 368- 370 (mit einem Überblick über die frühere Literatur). 
Jedoch nicht allein die thebanischen Sparten, Orestes und Octavian-Augustus werden in Claudians Panegyriken einer harschen Kritik unterzogen. In seiner Destruktion der historischen und mythischen Traditionen macht der Dichter nicht einmal vor dem römischen Nationalhelden Aeneas halt. Im ersten Buch der Laudes Stilichonis würdigt er Stilichos Erfolge gegen die Westgoten und die Bastarner, die die Ermordung von dessen Vorgänger Promotus übermütig gemacht habe (Stil. 1,94-108):

\section{[...] quis enim Visos in plaustra feroces \\ reppulit aut saeva Promoti caede tumentes \\ Bastarnas una potuit delere ruina? \\ Pallantis iugulum Turno moriente piavit \\ Aeneas, tractusque rotis ultricibus Hector \\ irato vindicta fuit vel quaestus Achilli: \\ tu neque vaesano raptas venalia curru \\ funera nec vanam corpus meditaris in unum \\ saevitiam: turmas equitum peditumque catervas \\ hostilesque globos tumulo prosternis amici; \\ inferiis gens tota datur. nec Mulciber auctor \\ mendacis clipei fabricataque vatibus arma \\ conatus iuvere tuos: tot barbara solus \\ milia iam pridem miseram vastantia Thracen \\ finibus exiguae vallis conclusa tenebas.}

Denn wer hat die wilden Westgoten zu ihren Wagen zurückgetrieben oder hat es vermocht, die Bastarner, die aufmüpfig geworden waren nach dem grausamen Mord an Promotus, in einer Niederlage zu vernichten? Pallas' durchgeschnittene Kehle sühnte Aeneas mit Turnus’ Tod, und Hektor, von den rächenden Wagenrädern mitgeschleift, war dem zornigen Achill Rache - oder sogar bares Geld! Du, Stilicho, reißt weder verkäufliche Leichen im Wahnsinn mit deinem Streitwagen fort noch ersinnst du ergebnislose Grausamkeit gegen einen einzigen Leichnam: Reiterschwadrone, Formationen von Fußtruppen und ganze feindliche Heerscharen streckst du nieder dem Grab deines Freundes: Ein ganzes Volk wird den Unterirdischen übereignet. Und nicht Vulkan war der Schöpfer eines Lügen-Schildes und nicht Waffen, die von Dichtern fabriziert wurden, unterstützten deine Unternehmungen: Allein hast du so viele tausende Barbaren, die schon seit langem das unglückliche Thrakien verwüsteten, in einem engen Tal eingeschlossen und dort festgehalten.

Zwei Verweise auf prominente mythische Helden, Aeneas und Achill, veranschaulichen in typischer Überbietungstopik Stilichos Leistung. ${ }^{80}$ Die Berichterstattung des Erzählers ist hierbei zunächst neutral: Aeneas habe, so führt er aus, Pallas’ Ermordung mit dem Tod des Turnus gesühnt, und auch der geschleifte Hektor sei Gegenstand von Achills Rache gewesen: Pallantis iugulum Turno moriente piavit / Aeneas tractusque rotis ultricibus Hector / irato (sc. Achilli) vindicta fuit (1,97-99). In den folgenden Ausführungen wechselt der Tonfall: Achill, so macht der Erzähler in einem nachgeschobenen vel quaestus Achilli $(1,100)$ deutlich, ging es mit der Ermordung Hektors nicht nur um Rache, vindicta, sondern vor allem um schnöden Gewinn - eine An- 


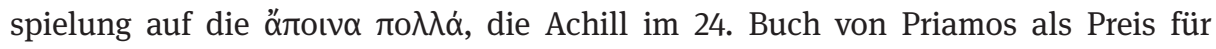
Hektors Leiche entgegennimmt. ${ }^{81}$ Im Folgenden verkehrt sich die Darstellung vollends ins Negative, indem materielle und unkontrollierte emotionale Aspekte zunehmend Oberhand gewinnen: Achills Wagen wird zu einem vaesanus currus, die Leiche Hektors zu corpora venalia, die Ermordung des Kriegsgegners zu einer vana saevitia. Achills Taten fungieren nur noch als Negativfolie, gegen die sich Stilicho abheben kann, wie das dreimalige neque - nec - nec zeigt. Schließlich werden Stilichos Leistungen denen Achills gegenübergestellt: Am Grab seines Freundes habe Stilicho Reiterschwadronen und Scharen von Fußtruppen hingestreckt (turmas equitum peditumque catervas:1,102) und dem ermordeten Promotus sogar ein ganzes Volk als Totengabe dargebracht: inferiis gens tota datur (1,104). Im Folgenden wechselt die Darstellung auf eine andere Ebene, auf der der Dichter wiederum den Topos von der Fiktionalität des Mythos aufruft. Anders als die mythischen Helden habe Stilicho nicht über einen von Vulcanus gefertigten Lügen-Schild (mendax clipeus, vgl. 1,105) und über Waffen verfügt, die ohnehin nur der Phantasie der Dichter entsprungen seien (fabricata vatibus arma: 1,105), sondern sei allein gegen Tausende von Barbaren angetreten: tot barbara solus / milia ... conclusa tenebas (1,106-108). Zu der quantitativen Überbietung - ein Toter gegen ein ganzes Volk - kommt eine qualitative: Der Mythos, ohnehin ein Lügengespinst der Dichter mit moralisch fragwürdigen und ohne göttliche Hilfe kaum kampffähigen Helden, verblasst angesichts der Leistungen Stilichos. Die Benennung Vulcans mit dem urrömischen Namen Mulciber $(1,107),{ }^{82}$ die Bezeichnung des Schildes als clipeus $(1,108)^{83}$ und vielleicht sogar die Bezeichnung der Dichter als vates $(1,108)$ legen es zudem nahe, vor allem den letzten Teil der Mythendestruktion auch auf Aeneas und seine Darstellung durch Vergil zu beziehen. Hier zeigt sich deutlich, dass nicht einmal mehr die nationalrömische mythische Vergangenheit für den Dichter einen Eigenwert besitzt, sondern lediglich noch ein Referenzpunkt für eine Gegenwart ist, die von dem einzig echten und wahren Helden, von Stilicho, überstrahlt wird. Mit Stilicho, das ist die Stoßrichtung dieses wie vieler anderer mythologischer Vergleiche Claudians, bricht ein Zeitalter an, das die pagane Mythologie Griechenlands und Roms hinter sich lässt und ihrer nicht mehr bedarf.

Dass die Demaskierung des Mythos als Repräsentation einer primitiven Frühzeit mit verdrehten, längst nicht mehr gültigen Wert- und Normvorstellungen christlichen Normen insgesamt nicht zuwiderläuft, ist unzweifelhaft. Speziell die Demontage der wichtigsten epischen Helden Achill und Aeneas berührt sich jedoch ausdrücklich mit christlicher Mythenkritik. Lactanz hatte im fünften Buch seiner Divinae institutiones das Bild des pius Aeneas systematisch destruiert. Im Rahmen seiner Reflexionen über Gerechtigkeit hatte er nachgewiesen, dass Aeneas das Epitheton pius nicht verdient habe. Der Held, den der Dichter nämlich selber als „Mann von hervorragender

81 Hom. Il. 24,555f.

82 J. Scherf, s.v. Mulciber, DNP 8 (2000), $457 \mathrm{f}$.

83 Unmittelbar zur Bezeichnung von Aeneas' neugeschmiedetem Schild Verg. Aen. 8,447; 8,625; 8,729. 
Frömmigkeit“, als insignem pietate virum ausweise, habe nach dem Tod des Pallas Gefangene gemacht, die er als Menschenopfer darbringen wollte; außerdem habe er dem Turnus die erflehte Gnade verweigert (Lact. inst. 5,10): ${ }^{84}$

quid quod bonus Aeneas haud aspernanda precantis trucidauit? adiuratus enim per eundem patrem et spes surgentis Iuli, nequaquam pepercit

furiis accensus et ira.

quisquamne igitur hunc putet aliquid in se uirtutis habuisse, qui et furore tamquam stipula exarserit et manium patris per quem rogabatur oblitus iram frenare non quierit? nullo igitur modo pius, qui non tantum non repugnantes, sed etiam precantes interemit.

Was ist damit, dass „der treffliche Aeneas Leute“ umbrachte, die „nicht zu Verachtendes erbaten“? Beschworen nämlich bei demselben Vater und „der Hoffnung des aufwachsenden Iulus“, gewährte er keineswegs Schonung, „von Wüten entflammt und vom Zorne“. Könnte also irgendwer glauben, dass dieser einen Funken von Anstand (virtus) in sich gehabt habe, der in Raserei wie ein Strohhalm aufloderte und die Manen des Vaters, bei dem er gebeten wurde, vergaß und seinen Zorn nicht zügeln konnte? In keinster Weise ist also einer fromm (pius), der nicht nur Menschen, die sich nicht wehrten, tötete, sondern sogar solche, die um Gnade baten.

Aeneas, so führt Lactanz aus, sei „wie ein Strohhalm in Raserei entbrannt“ (furore velut stipula exarsit) und habe seinen Zorn nicht zügeln können (iram frenare), er, der sogar um Gnade Flehende getötet habe, könne nicht pius genannt werden. Das Vergil-Zitat furiis accensus et ira aus den Schlussversen der Aeneis (Aen. 12,946) deutet darauf hin, dass Lactanz hier vor allem an die Tötung des Turnus denkt. Vor dem Hintergrund dieser Kritik erscheint die claudianische Formulierung Pallantis iugulum Turno moriente piavit / Aeneas $(1,97)$ in einem etwas anderen Licht: Die Tötung des Turnus war trotz des Verbums piare, das den Aeneas gegenüber Achill zunächst positiv zu konturieren scheint, kein Akt der pietas. Die Adjektive ultrix (1,98), iratus (1,99) und vaesanus (1,100), mit denen Claudian im weiteren Verlauf seiner Ausführungen das Verhalten des Achill belegt, entsprechen der lactanzischen Mythenkritik, indem sie den ungesunden furor des epischen Helden verurteilen.

Wenn Claudian dann dem Stilicho bescheinigt, er habe sich eben nicht zu „eitler Grausamkeit“, vana saevitia (1,101f.), hinreißen lassen, sondern vielmehr turmas equitum peditumque catervas / hostilesque globos (1,102f.) dem Begräbnis seines Freundes dargebracht, und wenn er im Folgenden von den marodierenden Barbarenhorden spricht, die Stilicho allein bezwungen habe (tot barbara solus / milia iam pridem miseram vastantia Thracen, 1,106f.), dann liefert er nicht nur eine quantitative Überbietung des Mythos, sondern entlastet Stilicho von jeglicher Kritik, einen Krieg geführt zu haben, der gegen christliche Normen verstößt: Stilicho tritt an zu einem

84 Zur christlichen, resp. lactanzischen Vergilkritik vgl. A. Wlosok, Der Held als Ärgernis: Vergils Aeneas, Würzburger Jahrbücher für die Altertumswissenschaft NF 8 (1982), 9-21; dies., Zwei Beispiele frühchristlicher ,Vergilrezeption'. Polemik (Lact. div. inst. 5,10) und Usurpation (Or. Const. 19-21), in: V. Pöschl (Hrsg.), 2000 Jahre Vergil, Wiesbaden 1983, 63-86; J. Walter, Pagane Texte und Wertvorstellungen bei Lactanz, Göttingen 2006 (Hypomnemata 165), 123. 
Krieg gegen einen an sich überlegenen äußeren Feind (hostiles globos, 1,104), mit dem er ein ihm widerfahrenes Unrecht rächt; er tut nur das, was er aus Gründen der Staatsräson tun muss und führt auch nach dem Konzept Augustins ein bellum iustum. ${ }^{85}$ Claudian erweist seinen Protagonisten also an dieser Stelle als fähigen Feldherrn und als moralisch integre Figur, die sich in ihrem Verhalten zu den christlichen Normen konform verhält. An die Stelle des längst obsoleten pius Aeneas tritt ein pius Stilicho - auch dies ein Hinweis auf die neue Zeit, die unter seiner Vormundschaft anbricht.

\section{Ergebnisse}

Kehren wir abschließend zum Ausgangspunkt unserer Untersuchung zurück. Die Integration paganer Mythen in Claudians politische Dichtungen, das haben die Betrachtungen meines Erachtens deutlich gezeigt, ist kein Hinweis auf eine pagane Gesinnung Claudians. Vielmehr kann man beobachten, dass der Dichter den Mythos, der für seine nichtchristlichen und seine christlichen Rezipienten gleichermaßen Bestandteil der Bildungstradition ist, in vielfältiger Weise funktionalisiert und in den Dienst seiner panegyrischen Aussagen stellt. Er tut dies, ohne gegen christliche Normen zu verstoßen: Sei es, indem er aus einer mythischen Geographie aktuelle Herrschaftsansprüche ableitet, die spätantiken Herrscher mit mythologischen Chiffren belegt oder die Adressaten seiner Gedichte durch konsequentes Überbieten der mythischen Vorgaben überhöht.

Claudians zahlreiche Verweise auf den Mythos dienen somit nicht dazu, die Normativität der mythischen Welt zu tradieren und dem Rezipienten als ein idealtypisches Paradigma vor Augen zu führen. Vielmehr zieht der Dichter eine klare Grenze zwischen der mythischen Vergangenheit und der zeitgeschichtlichen Realität, um auf dieser Basis die mythischen Figuren und Ereignisse gegen die Figuren und Ereignisse seiner Gedichte auszuspielen. Die Adressaten von Claudians Gedichten stehen über dem Mythos und vermögen seine Exemplarität und Normativität durch ihr vorbildliches Verhalten auf Dauer sogar zu ersetzen. Davon, dass Claudian „chantait avec trop de ferveur la mythologie“, wie Émilienne Demougeot es formuliert hat, ${ }^{86} \mathrm{kann}$ also keine Rede sein; auch sind „Claudians glutvolle Epen ... mit ihrem mythologischen Prunk“ weit davon entfernt, „ein einziger Triumph des Paganismus“ zu sein, wie Manfred Fuhrmann im Anschluss an Wolfgang Schmid schreibt. ${ }^{87}$ Es geht Claudian gerade nicht darum, den Mythos zu stabilisieren, sondern darum, auf der Ebene der

85 Aug. quaest. hept. 6,10: iusta autem bella ea definiri solent quae ulciscuntur iniurias, si qua gens vel civitas, quae bello petenda est, vel vindicare neglexerit quod a suis inprobe factum est vel reddere quod per iniurias ablatum est. Zum bellum iustum als Topos der Panegyrik Mause (s. Anm. 38), $189 \mathrm{f}$.

86 E. Demougeot, De l'unité à la division de l'empire romain (395-410). Essai sur le gouvernement impérial, Paris 1951, 288.

87 W. Schmid, s.v. Claudian, LAW, 638-640, 639; zustimmend Fuhrmann (s. Anm. 66), 145. 
literarischen Darstellung einen Paradigmenwechsel zu propagieren: den Wechsel vom ,mythischen` zum ,politischen' Helden, der des mythischen Vorbilds nicht mehr bedarf und dessen Handeln keinerlei Widersprüche zu christlichen Norm- und Wertvorstellungen aufweist. Die Beibehaltung paganer Mythen und das vorübergehende Akzeptieren der normativen Kraft, die von ihnen ausgeht, ist dabei für Claudian paradoxerweise das Mittel der Wahl, den in der paganen Tradition erzogenen Rezipienten diesen Paradigmenwechsel anzuzeigen. 